\title{
Preventive nutritional supplementation throughout the reproductive life cycle
}

\author{
Joan Fernández-Ballart* and Michelle M Murphy \\ Preventive Medicine and Public Health, Faculty of Medicine and Health Sciences, Rovira i Virgili University, \\ Sant Llorenç 21, E-43201 Reus, Spain
}

\begin{abstract}
Current interest in preventive nutritional supplementation strategies during the reproductive cycle in developed countries focuses mainly on iron and folic acid. Iron deficiency is the most common cause of anaemia. Inadequate iron nutrition is mainly a problem in developing countries but it also seems to affect a large proportion of pregnant women in the industrialised world. There is no chance for diet modification alone to meet iron requirements during pregnancy. However, dietary advice must be provided to increase iron intake and iron bioavailability. The best choice is prescribed supplementation adapted to the individual's needs.

Folic acid supplementation during the periconceptional period reduces the occurrence and recurrence of neural tube defects (NTDs). According to the updated edition of American Dietary Reference Intakes, recommended dietary allowance for folate for women of childbearing age varies throughout the reproductive cycle from $400 \mu \mathrm{g} \mathrm{day}^{-1}$ of dietary folate equivalents (DFEs) for non-pregnant women, to $600 \mu \mathrm{g} \mathrm{day}^{-1}$ DFEs for pregnant women and $500 \mu \mathrm{g} \mathrm{day}^{-1}$ DFEs in lactating women. Increasing dietary folate, fortifying staple foods with folic acid or use of folic acid supplements can increase folate intake.
\end{abstract}

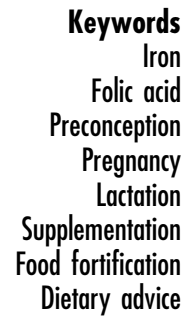

Current interest in preventive nutritional supplementation strategies during the reproductive cycle in developed countries focuses mainly on iron and folic acid.

\section{Iron}

Iron deficiency is the most common cause of anaemia. Inadequate iron nutrition is mainly a problem in developing countries but it also seems to affect a large proportion of pregnant women in the industrialised world because most of them start pregnancy with low or completely depleted iron stores ${ }^{1}$.

Even if the evidence is far from conclusive, adverse effects of iron deficiency and iron deficiency anaemia during pregnancy have been reported for both the pregnant mother and her foetus. They include increased maternal mortality, morbidity (increased fatigue, decreased work capacity, reduced resistance to cold, poor tolerance to heavy blood loss, increased risk of urinary tract infections, etc. $)^{2}$, and undesirable pregnancy outcomes (perinatal death, pre-term delivery, low birth weight, pre-eclampsia) ${ }^{3}$. However, higher than normal haemoglobin concentrations have also been related with pregnancy complications ${ }^{4}$.

Throughout the reproductive cycle we must provide enough iron to ensure optimal pre-pregnancy reserves, preventing iron deficiency during gestation and supporting iron replenishment during lactation. Using the factorial method, the total iron cost of a normal fullterm pregnancy has been estimated to be approximately $1000 \mathrm{mg}$ and the extra requirements to be approximately $400 \mathrm{mg}$ for 40 weeks of pregnancy plus 25 weeks of lactation (17 without menstruation $)^{5}$. The extra requirements of pregnancy could be provided by an extra $3.3 \mathrm{mg}$ daily of absorbed iron during the last 6 months of pregnancy. Alternatively the extra requirements of a full reproductive cycle can be met by an extra $0.9 \mathrm{mg}$ daily throughout the full reproductive cycle.

However, it has been suggested that iron needs during the reproductive cycle may be seriously overestimated ${ }^{6}$. The estimated needs mainly depend on the target haemoglobin concentration considered. Perhaps the current goal of maintaining a mean of $130 \mathrm{~g} \mathrm{l}^{-1}$ of haemoglobin (the maximum concentration that can be achieved by supplementation) is excessive and unnecessary. The above-mentioned effects in mothers and infants are reported at concentrations below $110 \mathrm{~g} \mathrm{l}^{-1}$ (the accepted level of anaemia). Also, to accomplish the goal of maximum concentration that can be achieved by supplementation, it would be necessary to give very high doses of iron because the bioavailability decreases dramatically when iron stores increase. 
The iron status indicators used are different between surveys. In the case of serum ferritin (cut-off values varying from $10 \mu \mathrm{g} \mathrm{l}^{-1}$ to $17 \mu \mathrm{g} \mathrm{l}^{-1}$ ), the prevalence of iron deficiency in adult menstruating women in Europe has been reported to be between 3.9\% in Iceland and 45\% in Ireland ${ }^{7}$. This figure has been between $15 \%$ and $30 \%$ in the majority of countries. In a review of the different studies on Spanish women ${ }^{8}$ of childbearing age, the prevalence of iron deficiency was $15.4 \%$ and iron deficiency anaemia was $2.3 \%$. The iron bioavailability of Spanish meals has been reported to be higher than in Northern European countries ${ }^{9}$ and this could be, in part, the reason for lower iron deficiency rates despite a similar iron intake.

If we accept the iron needs usually reported, there is no chance for diet modification alone to meet the requirements because they are too high to fulfil with reasonable dietary advice. However, dietary advice must be provided to increase iron intake and iron bioavailability.

Iron fortification of foods with the amount of iron necessary to supply to pregnant women is problematic. It may give rise to excessive quantities for other population groups, such as adult men or people genetically predisposed to haemochromatosis (up to $10 \%$ of the population).

The best choice is prescribed supplementation adapted to the individual's needs. It has been demonstrated that an excessive drop in haemoglobin during pregnancy can be prevented by iron supplementation. Current iron supplementation recommendations state that it is necessary to give either a daily dose of 30 to $60 \mathrm{mg}$ Fe or a weekly dose of $120 \mathrm{mg} \mathrm{Fe}$ in the form of ferrous salt ${ }^{10}$. Higher doses are unnecessary for prophylaxis and are associated with greater secondary effects and less compliance. The studies that compare daily with weekly dose strategies are still inconclusive but it seems that a daily dose would be more appropriate. The best time to start supplementation is prior to conception. There is no reason to delay preventive supplementation to the second half of pregnancy in women with non-optimal iron reserves, even if they are not clearly anaemic. Iron supplements can impair absorption of other nutrients such as zinc that may also be necessary to supplement.

\section{Folic acid}

Folic acid supplementation during the periconceptional period reduces the occurrence ${ }^{11}$ and recurrence of neural tube defects (NTDs) ${ }^{12}$. The American recommended dietary allowance for folate in women of childbearing age varies throughout the reproductive cycle from $400 \mu \mathrm{g} \mathrm{day}^{-1}$ of dietary folate equivalents (DFEs) for non-pregnant women, to $600 \mu \mathrm{g} \mathrm{day}^{-1}$ DFEs for pregnant women and $500 \mu \mathrm{g}$ day $^{-1}$ DFEs in lactating women. There has been considerable debate on the appropriate level of folic acid supplementation required before and throughout pregnancy, whether supplementation is required in all populations, and what would be the most effective way to ensure that optimal folate status is achieved in high-risk groups (history of NTDs, low socioeconomic status). Increasing dietary folate, fortifying staple foods with folic acid or use of folic acid supplements can improve folate status.

The effect of each of these strategies on red cell folate levels, the most appropriate indicator of folate status that reflects intracellular levels as well as folate turnover during the previous 120 days, has been tested ${ }^{13}$. The results showed that consumption of equivalent folate levels either by folic acid supplementation, by consumption of folic-acid-fortified foods or by consumption of dietary folate had different effects on red cell folate. While mean red cell folate was significantly increased in the supplemented and fortified groups, there was little change in the dietary group. The authors suggested that this is due to the lower bioavailability of dietary folate when compared with synthetic folic acid.

The US Centers for Disease Control and Prevention recommendation on the use of folic acid supplements by women of childbearing age advises against the consumption of more than $1 \mathrm{mg}$ of folic acid daily. This is to avoid the risk of correcting the anaemia of vitamin $B_{12}$ deficiency, which would allow the neuropathy that accompanies this condition to go undiagnosed ${ }^{14}$. Since a high percentage of pregnancies are unplanned, all women with the possibility of becoming pregnant should take folic acid supplements in order for folic acid supplementation to work on a population level. Although health authorities in the UK were given guidance on the use of periconceptional folic acid supplementation in 1991 and despite the launching of the UK Health Education Authority awareness campaign in 1996, there has not been a decline in NTD rates ${ }^{15}$. The authors blame unplanned pregnancies and lack of compliance and knowledge by the women who would most benefit from the use of folic acid supplements.

The FDA policy to fortify all grains with $140 \mu \mathrm{g}$ of folic acid per $100 \mathrm{~g}$ of grain products aims to ensure that target groups of the population will increase their daily folic acid intake by at least $100 \mu \mathrm{g} \mathrm{day}^{-1}$, providing an upper limit of $1000 \mu \mathrm{g} \mathrm{day}{ }^{-1}$ to non-target groups. Increasing folic acid intake by $100 \mu \mathrm{g} \mathrm{day}^{-1}$ has been shown to improve red cell folate status and to reduce the risk of NTDs by more than $20 \%$ in a clinical trial ${ }^{16}$.

There is little information available on the folate status of women of childbearing age in Spain. The only reports provide information on estimated dietary folate intake but not analytical data on red cell folate status. Mean folate intake, estimated by 24-hour recall and food-frequency questionnaire in a representative sample of 1014 women from the population of Catalonia, varied from $282 \mu \mathrm{g} \mathrm{day}^{-1}$ in $18-34$-year-old to $317 \mu \mathrm{g} \mathrm{day}^{-1}$ in 35-49-year-old women ${ }^{17}$. Mean folate intake of 
$392 \mu \mathrm{g} \mathrm{day}^{-1}$ in 538 female participants aged $15-44$ years was reported in the Nutrition Survey of Valencia ${ }^{18}$. These folate intakes will mainly refer to naturally occurring folate in the diet. There is no policy recommending the use of folic acid supplements periconceptionally nor during pregnancy in Spain. Neither are grain products fortified with folic acid. The consumption of fortified breakfast cereals is low in Spain compared with other countries.

Red cell folate (RCF) levels of $400 \mathrm{ng} \mathrm{ml}^{-1}$ or more offer optimal protection against NTD-affected pregnancies. Below this level the risk of NTD per 1000 births can be graded into four categories ${ }^{19}$. We studied red cell folate status in a representative sample of 122 women aged 18-45 years from a Catalonian Mediterranean village population (HOMFOL Study, preliminary unpublished results). According to the results of Daly et al. ${ }^{19}$, $2.5 \%$ of our population would have a risk of 6.6 $\left(\mathrm{RCF}<150 \mathrm{ng} \mathrm{ml}^{-1}\right), 4.1 \%$ would have a risk of 3.2 (RCF between 150 and $199 \mathrm{ng} \mathrm{ml}^{-1}$ ), 33.6\% would have a risk of 2.3 (RCF between 200 and $299 \mathrm{ng} \mathrm{ml}^{-1}$ ) and 26.2\% would have a risk of 1.6 (RCF between 300 and $399 \mathrm{ng} \mathrm{ml}^{-1}$ ) of an NTD-affected pregnancy based on RCF status. In addition to sub-optimal folate status, homozygosity for the C677T polymorphism of the methylene tetrahydrofolate reductase (MTHFR) gene is a risk factor for NTD-affected pregnancies ${ }^{20}$. This polymorphism impairs the remethylation of homocysteine to methionine, thus causing elevated plasma homocysteine. Thus the homozygote (TT) form of this polymorphism results in increased requirements for folic acid. The MTHFR genotype distribution in our 18-45-year-old female population (HOMFOL) was as follows: wild type, CC: 41.0\%; heterozygote, CT: 48.4\%; TT, 10.6\%. The combination of mutant MTHFR genotype and low folate status may be a greater risk factor for NTDs than either variable alone ${ }^{21}$. These preliminary findings suggest that this Mediterranean population of women should increase their daily intake of folic acid in order to reduce the risk of having NTD-affected pregnancies.

Given the difficulties experienced in other countries with compliance to supplementation policies, we propose that the most practical strategy to prevent NTDs in Spain would be that of fortification. Women of childbearing age in Spain would benefit from the fortification of cereals and grains at the level used in the USA since January 1, 1998. Advice on the use of a periconceptional supplement of $400 \mu \mathrm{g}$ day $^{-1}$ of folic acid should also be offered. Since fortification would affect the whole population, it would also be beneficial to men and post-menopausal women as it would reduce plasma homocysteine. The overall benefits of this policy on a population basis would be to reduce the incidence of NTD-affected pregnancies and diseases associated with elevated plasma homocysteine such as cardiovascular diseases.

\section{Acknowledgement}

We wish to acknowledge the financial support of the Comisión Interministerial de Ciencia y Tecnología (CICYT: ALI 89-0388) and the Fondo de Investigación Sanitaria (FIS: 00/0954), Spain.

\section{References}

1 Institute of Medicine. Iron nutrition during pregnancy. In: Nutrition During Pregnancy. Washington, DC: National Academy Press, 1990; 272-98

2 Hercberg S, Galan P, Preziosi P, Aissa M. Consequences of iron deficiency in pregnant women: current issues. Clin. Drug. Invest. 2000; 19(Suppl.): 1-7.

3 Viteri FE. The consequences of iron deficiency and anemia in pregnancy. In: Allen L, King J, Lönnerdal B, eds. Nutrient Regulation During Pregnancy, Lactation and Infant Growth. New York: Plenum Press, 1994; 127-39.

4 Yip R. Significance of an abnormally low or high hemoglobin concentration during pregnancy: special consideration of iron nutrition. Am. J. Clin. Nutr. 2000; 72(Suppl.): 272S-9S.

5 Fernández-Ballart J. Iron metabolism during pregnancy. Clin. Drug. Invest. 2000; 19: 9-19.

6 Beaton GH. Iron needs during pregnancy: do we need to rethink our targets. Am. J. Clin. Nutr. 2000; 72(Suppl.): 265S-71S.

7 Hallberg L. Results of surveys to assess iron status in Europe. Nutr. Rev. 1995; 53: 314-22.

8 Arija V, Fernández-Ballart J, Salas J. Iron deficiency and iron deficiency anemia in the Spanish population. Med. Clin. (Barc.) 1997; 109: 425-30.

9 Galán P, Cherouvier F, Fernández-Ballart J, Martí-Henneberg C, Herceberg S. Biovailability and iron density in French and Spanish meals. Eur. J. Clin. Nutr. 1990; 44: 15763.

10 UNICEF/UNU/WHO/MI. Preventing Iron Deficiency in Women and Children: Technical Consensus on Key Issues and Resources for Programme Advocacy, Planning, and Implementation Technical Workshop. New York: UNICEF, 1999.

11 Czeizel AE, Dudás I. Prevention of the first occurrence of neural-tube defects by periconceptional vitamin supplementation. N. Engl. J. Med. 1992; 327: 1832-5.

12 MRC Vitamin Study Research Group. Prevention of neural tube defects: results of the Medical Research Council Vitamin Study. Lancet 1991; 338: 131-7.

13 Cuskelly GC, McNulty H, Scott JM. Effect of increasing dietary folate on red cell folate: implications for prevention of neural tube defects. Lancet 1996; 347: 657-9.

14 Centers for Disease Control and Prevention. Recommendations for the use of folic acid to reduce the number of spina bifida cases and other neural tube defects. MMWR Morb. Mortal. Wkly. Rep. 1992; 41(RR-14): 1-7.

15 Abramsky L, Botting B, Chapple J, Stone D. Has advice on periconceptional folate supplementation reduced neural tube defects? Lancet 1999; 354: 998-9.

16 Daly S, Mills JL, Molloy AM, Conley M, Lee YJ, Kirke PN, Weir DG, Scott JM. Minimum effective dose of folic acid for food fortification to prevent neural-tube defects. Lancet 1997; 350: 1666-9.

17 De Bree A, van Dusseldorp M, Brouwer IA, van het Hof $\mathrm{KH}$, Steegers-Theunissen RPM. Folate intake in Europe: recommended, actual and desired intake. Eur. J. Clin. Nutr. 1997; 51: 643-60.

18 Vioque J, Quiles J, Garcia de la Hera M, Guillen M, Ponce E, 
Muñoz P, Folic acid ingestion and associated factors in adult women 15-44 years of age in the Valencian Community. Med. Clin. (Barc.) 2000; 114: 414-16.

19 Daly LE, Kirke PN, Molloy A, Weir DG, Scott JM. Folate levels and neural tube defects. JAMA 1995; 274: 16981702.

20 Whitehead AS, Gallagher P, Mills JL, Kirke PN, Burke H, Molloy AM, Weir DG, Shields DC, Scott JM. A genetic defect in 5,10-methylenetetrahydrofolate reductase in neural tube defects. QJM 1995; 88: 763-6.

21 Christensen B, Arbour L, Tran P, Leclerc D, Sabbaghian N, Platt R, Gilfix BM, Rosenblatt DS, Gravel RA, Forbes P, Rozen R. Genetic polymorphisms in methylenetetrahydrofolate reductase and methionine synthase, folate levels in red blood cells and risk of neural tube defects. Am.J. Med. Genet. 1999; 84: 151-7. 